\title{
PENGARUH KUALITAS PELAYANAN PRAKTIK REHABILITASI BERSUMBERDAYA MASYARAKAT (RBM) TERHADAP KEPUASAN ORANGTUA/ KELUARGA PASIEN DI KECAMATAN GONDANGREJO KABUPATEN KARANGANYAR
}

\author{
Roy Romey Daulas M, Sudarman \\ Kementerian Kesehatan Politeknik Kesehatan Surakarta Jurusan Terapi Wicara \\ Diterima : 3 Oktober 2018, Disetujui : 9 Oktober 2018
}

\begin{abstract}
Background: The practice of Community Resource Rehabilitation (RBM) was carried out by Speech Therapy Department students in the area of the target village of the Therapy Department. The speech was from the Surakarta Ministry of Health Polytechnic in the Gondangrejo District. The RBM has a philosophical foundation from, by and for the community which implies that social rehabilitation activities carried out are initiated by the local government and the community where they are parents/ family and Disability itself which is directly carried out from, by and for the community. Based on the above, then along with the paradigm shift has changed the handling and range of services that were initially institutional-based based into community-based services. Method: This type of research is a quantitative study with an analytical observational design through a cross sectional approach (Cross Sectional. The population in this study was all parents/ families of patients in Godangrejo Subdistrict, Karanganyar District who have disability children or special needs who have received rehabilitation services Community Resources (RBM) by Speech Therapy Department students. Results: Univariate test results on variable Quality of service practices of RBM in general, showed that the majority of respondents rated the service quality of RBM practices by students as "quite good", namely $73.1 \%$, who rated "good" as much as $17.3 \%$, and who rated "bad" at 9.6\%. The univariate test results on the variable satisfaction of parents/ family patients in general, showed that the majority of respondents rated the satisfaction of parents/ families of patients classified as "quite good" which amounted to 55.8\%, which rated "good" by 15.4\%, and who rated "bad" 28.8\%. Conclusion: From the results of the bivariate test using "Spearman's rho" on the two variables, namely the variable quality of service RBM practice and satisfaction of parents/ families of patients in receiving RBM practice services, it indicates that there is a very significant relationship between the service quality of RBM practices and parental satisfaction/ family of patients in gondangrejo Subdistrict, this is indicated by the $p$ value of 0.000, which means that the $p$ value is $0.000 \leq 0.05$, with a positive correlation direction, between the service quality of RBM practices and the satisfaction of parents/ families of patients in Gondangrejo District. The strength of the relationship is "moderate" with the value of $r$ count 0.535 .
\end{abstract}

Keywords : Community Resource Rehabilitation (RBM), Satisfaction Of Parents/ Families Of Patients 


\section{PENDAHULUAN}

Dewasa ini masih banyak kelemahan pelayanan publik termasuk dunia pendidikan sehingga belum memenuhi harapan masyarakat. Pemenuhan harapan masyarakat tersebut merupakan tujuan utama dari fungsi pelayanan publik yang harus selalu ditingkatkan, baik dari sisi kuantitas maupun dari sisi kualitas. Lembaga pendidikan merupakan organisasi publik agar dapat memberikan pelayanan yang berkualitas diperlukan adanya perubahan sumber daya yang dimiliki, berupa perbaikan perangkat pelayanan dan memaksimalkan peran pelayan yang ada. Langkah yang perlu ditempuh oleh lembaga pendidikan untuk meningkatkan pelayanan tersebut adalah mengoptimalkan kemampuan sumber daya manusianya serta peningkatan sarana dan prasarana yang mendukung kelancaran pelayanan pendidikan. Pemerintah terus berusaha memperioritaskan pembangunan dibidang pendidikan, khususnya kualitas pendidikan agar dapat menghasilkan sumber daya manusia yang berkualitas dan produktif. Lembaga pendidikan mempunyai fungsi utama menyediakan lulusan, bukan saja dalam jumlah banyak tetapi juga berkualitas dan disiplin tinggi, mampu menjadi dinamisator, inovator, motivator dan penggerak pembangunan serta memproduksi tenaga-tenaga kerja yang berkualitas untuk berbagai jenis dan tingkatan keahlian.

Kualitas pelayanan merupakan suatu driver kepuasan yang bersifat multidimensi. Tingkat kualitas pelayanan tidak dapat dinilai berdasarkan sudut pandang perusahaan tetapi harus dipandang dari sudut pandang penilaian pelanggan. Kepuasan dari sisi konsumen dipandang baik apabila memenuhi apa yang mereka harapkan, sebaliknya pelayanan akan dipersepsikan buruk apabila tidak memenuhi yang mereka harapkan (Kotler, 2000). Kepuasan pelanggan sebagai persepsi terhadap produk atau jasa yang telah memenuhi harapannya. Kotler (2005) mendefinisikan jasa sebagai setiap tindakan atau kinerja yang dapat ditawarkan oleh suatu pihak lain yang pada dasarnya bersifat intangible (tidak berwujud) dan tidak menghasilkan kepemilikan sesuatu.

Teori consumer behavior menyatakan bahwa kepuasan pelanggan adalah persepektif pengalaman konsumen setelah mengkonsumsi atau menggunakan produk atau jasa (Oliver, 1993). Kepuasan pelanggan diharapkan akan berpengaruh terhadap loyalitas. Pelanggan yang loyal dapat memberikan keuntungan yang besar terhadap organisasi. Penyelengaraan pendidikan selayaknya mencermati kualitas pelayanan. Kegiatan pendidikan tidak hanya diorientasikan pada hasil akhir proses pendidikan, melainkan juga melalui pembuktian akuntabilitas yang baik meliputi jaminan kualitas (quality assurance), pengendalian kualitas (quality control), dan perbaikan kualitas (quality improvement) (Badan Akreditasi Nasional Perguruan Tinggi, 1998).

Pelayanan merupakan kegiatan yang tidak dapat didefinisikan secara tersendiri yang pada hakikatnya bersifat intangible (tidak teraba), yang merupakan pemenuhan kebutuhan dan tidak harus terikat pada penjualan produk atau pelayanan lain. Swastha DH (1998) mendefinisikan jasa (pelayanan) adalah: Barang yang tidak kentara (intangible product) yang dibeli dan dijual di pasar melalui suatu transaksi pertukaran yang saling memuaskan. Rangkuti (2002) 
menyatakan, jasa merupakan pemberian suatu kinerja atau tindakan tak kasat mata dari satu pihak kepada pihak lain. Pelayanan adalah setiap tindakan atau perbuatan yang menghasilkan suatu tingkat kepuasan yang dapat ditawarkan untuk dijual, bersifat intangible, inseparable, variable dan perishable.

Wyckoff dalam Tjiptono (2000) menyatakan kualitas pelayanan adalah tingkat keunggulan yang diharapkan dan pengendalian atas tingkat keunggulan tersebut untuk memenuhi keinginan pelanggan. Sedangkan Yamit (2001) menyatakan secara umum kualitas jasa pelayanan adalah dapat dilihat dari perbandingan antara harapan konsumen dengan kinerja jasa pelayanan. Pelayanan terbaik pada pelanggan (excellent) dan tingkat kualitas pelayanan merupakan cara terbaik yang konsisten untuk dapat mempertemukan harapan konsumen (standar pelayanan eksternal dan biaya) dan sistem kinerja cara pelayanan (standar pelayanan internal, biaya dan keuntungan). Dari penjelasan para ahli tentang dimensi kualitas pelayanan, maka dapat di simpulkan beberapa dimensi yang sesuai agar pelayanan dapat memberikan kepuasan kepada para pelanggan. Adapun dimensi tersebut diantaranya bukti fisik (tangible), keandalan (reliability), ketanggapan (responsiveness), jaminan (assurance) serta empati (emphaty).

Poltekkes Kemenkes Surakarta merupakan lembaga pendidikan kesehatan milik Pemerintah yang menyelengarakan program pendidikan di bidang kesehatan dibawah Badan PPSDM Kemenkes RI yang berdiri sejak 16 juli 2002. Program Studi Terapi Wicara berdiri tahun 2005 dibawah Jurusan Okupasi Terapi yang kemudian pada tahun 2007 ditetapkan menjadi Jurusan Terapi Wicara. Jurusan
Terapi Wicara Poltekkes Kemenkes Surakarta merupakan satu-satunya pendidikan vokasi Terapi Wicara yang negeri (milik pemerintah) di Indonesia sehingga berpengaruh pada banyaknya peminat (calon mahasiswa) dan jumlah mahasiswa dibandingkan kedua lembaga pendidikan Terapi Wicara swasta yang lain (Profil Jurusan terapi Wicara, 2017).

Praktik Rehabilitasi Bersumber daya Masyarakat (RBM) mahasiswa Jurusan Terapi Wicara Poltekkes Surakarta menjadikan center of excellent dan sekaligus ciri dari Jurusan Terapi Wicara (Renop Jurusan Terapi Wicara, 2017). Praktik RBM mahasiswa Jurusan Terapi Wicara dilakukan di didaerah binaan Jurusan Terapi Wicara Poltekkes Kemenkes Surakarta yaitu di wilayah Kecamatan Gondangrejo. Praktik Rehabiltiasi Bersumberdaya Masyarakat (RBM) mahassiwa Jurusan Terapi Wicara merupakan perwujudan dari komitmen Jurusan Terapi Wicara dalam upaya meningkatkan taraf kesejahteraan sosial bagi disabilitas dituangkan dalam Undang-undang Republik Indonesia Nomor 8 Tahun 2016 tentang Penyandang Disabilitas, Undang-undang Republik Indonesia Nomor 11 tahun 2009 tentang Kesejahteraan Sosial serta adanya Konvensi PBB yang telah diratifikasi oleh Pemerintah Indonesia pada tanggal 10 Oktober 2011 yaitu Undang-Undang Republik Indonesia No. 19 Tahun 2011 tentang Pengesahan Convention On The Rights Of Persons With Disabilities (Konvensi Mengenai Hak-Hak Penyandang Disabilitas).

Pelayanan Praktik RBM

Mahasiswa Jurusan Terapi Wicara Poltekkes Kemenkes Surakarta

a. Prinsip Dasar 
1) Filosofi RBM : dari, oleh dan untuk masyarakat dengan melalui pembinaan wilayah dalam hal pelatihan/bimbingan teknis, pendamoingan,pemberdayaan Disabilitas, orangtua/keluarga, masyarakat dan rujukan kepada profesi tertentu dan pemerintah

2) RBM diselenggarakan sebagai upaya pencegahan, perlindungan, pengembangan sisa kemampuan yang ada/dimiliki, pemberdayaan, rehabilitasi dan resosialisasi serta peningkatan ekonomi

3) Pelibatan secara penuh Disabilitas, keluarga, masyarakat dan lingkungannya, mencakup seluruh usia dan tingkat kecacatan serta tidak memberdakan suku, ras maupun golongan

4) Peran keluarga dan masyarakat sebagai prakarsa, pelaksana, pembina dan bertanggung jawab dari perencanaan, monitoring, evaluasi, pencatatan dan pelaporan

5) Keluarga dan masyarakat adalah caregiver permanen dan sebagai penanggungjawab dan pelaku utama dalam RBM

6) Upaya memobilisasi potensi dan sumber kesejahteraan sosial (faktor sosial, kearifan lokal, ekonomi, budaya, geografi, demografi masyarakat dan kondisi riil Masyarakat)

b. Teknik Dasar RBM

1) Perkenalan

2) Inventarisasi

3) Bimbingan dan penyuluhan

4) Bimbingan musyawarah

5) Perencanaan RBM

6) Pelaksanaan supervisi dan evaluasi

c. Pendekatan
Pendekatan yang digunakan adalah pendekatan metode pekerjaan sosial :

1) Metode pendekatan individu

2) Pendekatan keluarga

3) Pendekatan kelompok

4) Pendekatan masyarakat

d. Tujuan

1) Penerimaan orangtua, keluarga dan masyarakat terhadap Disabilitas sebagai bagian dari keluarga dan masyarakat dan mampu memfasilitasi kemandirian Disabilitas sesuai dengan potensi dan sisa kemampuan yang ada

2) Meningkatnya kesadaran masyarakat dalam upaya peningkatan kesejahteraan sosial tidak hanya pada PMKS lainnya tetapi khusus Disabilitas.

3) Disabilitas mampu mengoptimalkan sisa kemampuan yang ada sehingga memiliki kemandirian baik secara sosial maupun ekonomis.

e. Sasaran

1) Individu dengan gangguan bahasa, bicara, suara, irama kelancaran dan menelan

2) Orangtua/keluarga

3) Masyarakat dan unsur-unsurnya

4) Potensi dan sumber daya lainnya

f. Strategi Pelaksanaan Rbm

1) Pemberdayaan sosial

Meningkatkan kemampuan orangtua/keluarga dan masyarakat dalam memberdayakan sumberdaya dan potensi yang ada yang meliputi manusia, sosial, lingkungan dan alam yang dimiliki dan berada di sekitarnya guna mengatasi dan mencari solusi pemecahan masalah guna pemenuhan 
kebutuhan Disabilitas RW dan Intelektual.

2) Kemitraan

Membangun

kerjasama, kepedulian, kebersamaan, kesetaraan dan jejaring kinerja serta kemitraan antara pemerintah pusat dan daerah, masyarakat, organisasi sosial, dunia usaha dan stakeholders lainnya dalam penyelenggaraan krehabilitasi social.

3) Partisipasi sosial

Adanya prakarasa, inisiatif dan keterlibatan secara langsung dan keterlibatan aktif seluruh komponen beserta unsure-unsur keluarga, masyarakat, dunia usaha serta stakeholders dalam penyelenggaraan rehabilitasi sosial.

4) Advokasi sosial

Adalah segala upaya yang dilakukan untuk memberikan perlindungan, pendampingan dan pembelaan atas-hak-hak penyandang disabilitas

5) Pembinaan wilayah Upaya menstrasnfer ilmu pengetahuan secara berjenjang dan bertahap sebagai media untuk mengoptimalkan dan memberdayakan penyandang disabilitas, potensi orangtua, keluarga dan masyarakat

g. Bentuk kegiatan RBM

1) Program pendidikan masyarakat, berupa penyuluhan, pelatihan, dan pendampingan berbagai aspek kesehatan di masyarakat

2) Pelayanan kesehatan kepada masyarakat, berupa kegiatan pendampingan keahlian, fasilitasi, intervensi kepada klien sesuai kompetensi profesi, konsultasi serta kerjasama

3) Permberdayaan masyarakat, yaitu kegiatan yang dilakukan bersama-sama dengan masyarakat dalam rangka pencegahan penyakit

4) Teknologi tepat guna, yaitu penerapan teknologi dibidang kesehatan yang bermanfaat untuk peningkatan taraf kesehatan masyarakat, dan dapat juga berupa tindak lanjut hasil-hasil penelitian yang mempunyai kemanfaatan tinggi bagi kesehatan masyarakat

5) Pengembangan kewirausahaan, yaitu suatu upaya menciptakan wirausaha baru mandiri yang berbasis ipteks yang sesuai dengan keahlian yang dapat dilaksanakan dalam bentuk pelatihan kewirausahaan, penempatan mahasiswa magang pada unit usaha dan menfasilitasi dosen atau mahasiswa dalam berwirausaha.

(Buku Pedoman Praktik RBM, 2018)

Fakta dilapangan menunjukan bahwa penerima/acceptance orang tua/ keluarga yang memiliki anggota keluarga dengan Disabilitas tidak semuanya baik atau menerima kondisi anaknya/ anggota keluarga yang demikian, karena Disabilitas dianggap sebagai "kutukan" atau gangguan makluk halus. Disisi lain masyarakat lebih banyak yang memandang dengan sebelah mata dan menganggap mereka adalah "benalu" atau sampah masyarakat, sehingga bersikap mengucilkan, apatis, kurang memberikan kesempatan bahkan eksploitasi baik fisik, mental atau sosial 
Permasalahan internal Disabilitas adalah rendah diri, merasa tidak berguna, menarik diri sehingga menghambat bagi dirinya untuk mengakses sumber-sumber yang ada. Permasalahan eksternal penanganan disabilitas mencakup rendahnya pemahaman masyarakat terhadap masalah kecacatan, stigma (kutukan, nasib), isolasi, dan perlindungan yang berlebihan, kurangnya peran keluarga dan masyarakat terhadap masalah disabilitas dan penanganannya, kurangnya Upaya Peningkatan Kesejahteraan Sosial (UPKS) Disabilitas khususnya di pedesaan, masih banyaknya orang dengan kecacatan yang hidup dibawah garis kemiskinan dan tingkat pendidikan yang sangat rendah serta masih banyak keluarga orang dengan kecacatan yang menyembunyikan/ menutupi bila memiliki anggota keluarga yang disabilitas.

Berdasarkan hal tersebut diatas, maka seiring dengan pergeseran paradigma telah mengubah penanganan dan jangkauan pelayanan yang semula berorientasi pada institusional based menjadi layanan community based. Hal ini dianggap lebih efektif dan efisien dikarenakan keluarga/ orang tua adalah sebagai caregiver permanent dalam pemberian layanan dan rehabilitasi kepada Disabilitas serta adanya dukungan masyarakat yang berupa upaya untuk kemandirian Disabilitas disertai Assesbilitas.

\section{METODE PENELITIAN}

Penelitian ini dilakukan di Kecamatan Godangrejo, Kabupaten Karanganyar, sebanyak 7 desa yang terdapat anak dengan disabilitas dan kebutuhun khusus. Penelitian ini telah dilaksanakan pada bulan April sampai
Agustus 2018. Populasi pada penelitian ini adalah seluruh orangtua/keluarga pasien yang memiliki anak disabilitas atau kebutuhan kehusus di Kecamatan Godangrejo, Kabupaten Karanganyar. Jenis penelitian ini adalah penelitian kuantitatif dengan rancangan analitic observational melalui pendekatan potong lintang (Cross Sectional), dalam penelitian ini tidak terdapat intervensi/perlakuan terhadap responden, dan hanya dilakukan pengukuran satu kali saja dan tidak melakukan tindak lanjut.

Variabel dalam penelitian ini adalah dengan menggunakan Variabel bebas/ independen dan variable terikat/ dependen. Variabel Bebas/ Independen Variable $(\mathrm{X})$ adalah kualitas pelayanan praktik RBM mahasiswa Jurusan Terapi Wicara. Variabel Terikat/Dependent variable (Y) adalah kepuasan orangtua/ keluarga pasien di kecamatan Gondangrejo.

Teknik pengambilan data menggunakan kuisioner yang diberikan kepada orangtua/ keluarga pasien di kecamatan Gondangrejo. Kemudian peneliti memberikan penjelasan singkat mengenai kuesioner tersebut dan meminta untuk mengisinya. Kemudian kuisioner dikumpulkan, diseleksi, diolah dan dianalisis.

Teknik analisa data, penulis menggunakan program Statistical Package for the Social Sciences (SPSS), yaitu pengujian dilakukan setelah mendapatkan data primer. Data hasil penelitian disajikan dalam bentuk tabel distribusi frekuensi dan persentase, tabel analisis bivariat dan narasi. Dalam penelitian ini, peneliti menggunakan kuesioner yang penulis buat sendiri untuk mengetahui pengaruh kualitas pelayanan praktik RBM mahasiswa Jurusan Terapi 
Wicara terhadap tingkat kepuasan orangtua/ keluarga pasien di Kecamatan Gondangrejo Kabuaten Karanganyar.

\section{HASIL PENELITIAN}

Dari hasil penelitian diketahui bahwa total sampel dalam penelitian ini adalah 52 responden yang tersebar di 8 desa di Kecamatan Gondangrejo, hasil penelitian menunjukkan bahwa mayoritas responden di Kecamatan Gondangrejo adalah perempuan yaitu sebesar $73.12 \%$ responden, sedangkan responden laki-laki sebesar 26.9\%. Berdasarkan umur responden, mayoritas responden pada penelitian ini berusia 31 s.d 40 tahun yaitu sebesar $55.8 \%$. Berdasarkan tingkat pendidikan responden diketahui bahwa mayoritas tingkat pendidikan responden adalah SLTA yaitu sebesar $61.5 \%$.

Dari hasil uji univariat pada masing-masing variabel diketahuia bahwa kualitas pelayanan praktik RBM pada aspek reliability (kehandalan) dari responden menilai "cukup" yaitu sebesar $69.2 \%$, yang menilai "baik" sebesar $15.4 \%$ dan yang "buruk" sebesar $13.5 \%$. Hasi uji univariat pada aspek Tangibel (Bukti fisik) menunjukan bahwa mayoritas responden menilai kemampuan bukti fisik yang diberikan oleh mahasiswa masih tergolong "cukup" yaitu sebesar $67.3 \%$, yang menilai "baik" sebesar $19.2 \%$, dan yang menilai "buruk" sebesar $13.5 \%$. Hasi uji univariat pada aspek daya tanggap (Responsiveness) menunjukan bahwa mayoritas responden menilai kemampuan Responsiveness yang tunjukan oleh mahasiswa masih tergolong "cukup" yaitu sebesar 42.3\%, yang menilai "baik" sebesar 19.2\%, dan yang menilai "buruk" sebesar 38.5\%. Hasi uji univariat pada aspek Jaminan (Assurance) menunjukan bahwa mayoritas responden menilai kemampuan Assurance yang diberikan oleh mahasiswa masih tergolong "cukup" yaitu sebesar $46.2 \%$, yang menilai "baik" sebesar $30.8 \%$, dan yang menilai "buruk" sebesar 23.1\%. Hasi uji univariat pada aspek Empati (Emphaty), menunjukan bahwa mayoritas responden menilai kemampuan Emphaty yang ditunjukan oleh mahasiswa masih tergolong "cukup" yaitu sebesar 73.1\%, yang menilai "baik" sebesar $15.4 \%$, dan yang menilai "buruk" sebesar $11.5 \%$. Hasi uji univariat pada variabel Kualitas pelayanan praktik RBM secara umum, menunjukan bahwa mayoritas responden menilai Kualitas pelayanan praktik RBM oleh mahasiswa tergolong "cukup baik" yaitu sebesar $73.1 \%$, yang menilai "baik" sebesar $17.3 \%$, dan yang menilai "buruk" sebesar $9.6 \%$. Sedangkan hasi uji univariat pada variabel kepuasan keluarga/orang tua pasien secara umum, menunjukkan bahwa mayoritas responden menilai kepuasan orang tua/ keluarga pasien tergolong "cukup baik" yaitu sebesar 55.8\%, yang menilai "baik" sebesar $15.4 \%$, dan yang menilai "buruk" sebesar $28.8 \%$.

Analisis Bivariat dilakukan dengan "Spearman's rho" (Sugiono,1999). Dengan menentukan nilai korelasi ( $r$ ) berkisar antara 1 sampai -1, maka nilai semakin mendekati 1 atau -1 berarti hubungan antara dua variabel semakin kuat, sebaliknya apabila nilai mendekati 0 berarti hubungan antara dua variabel semakin lemah. Sedangkan untuk menentukan penilaian kriteria pengambilan keputusan adalah jika $\rho<0.05$ berarti ada hubungan yang signifikan antara variable bebas dengan variable terikat. 


\section{Correlations}

\begin{tabular}{|c|c|c|c|c|}
\hline & & & $\begin{array}{c}\text { kepuasa } \\
\text { n_OR }\end{array}$ & $\begin{array}{l}\text { kualitas_ } \\
\text { pelayanan }\end{array}$ \\
\hline \multirow{7}{*}{$\begin{array}{l}\text { Spearman } \\
\text { 's rho }\end{array}$} & kepuasa & Correlation & & \\
\hline & n_OR & Coefficient & 1.000 & $.535^{* *}$ \\
\hline & & $\begin{array}{l}\text { Sig. (2- } \\
\text { tailed) }\end{array}$ & & .000 \\
\hline & & $\mathrm{N}$ & 52 & 52 \\
\hline & $\begin{array}{l}\text { kualitas } \\
\text { pelaya }\end{array}$ & $\begin{array}{l}\text { Correlation } \\
\text { Coefficient }\end{array}$ & $.535^{* *}$ & 1.000 \\
\hline & nan & $\begin{array}{l}\text { Sig. (2- } \\
\text { tailed) }\end{array}$ & .000 & \\
\hline & & $\mathrm{N}$ & 52 & 52 \\
\hline
\end{tabular}

Berdasarkan tabel diatas, diketahui bahwa uji statistik korelasi dengan menggunakan analisis "Spearman's rho" pada variabel kualitas pelayanan praktik RBM dengan kepuasan orang tua klien diperoleh nilai $p$ value 0.000 , yang berarti nilai $p$ value $0.000 \leq 0.05$, hal ini menunjukan ada hubungan yang sangat signifikan antara kualitas pelayanan praktik RBM dengan kepuasan orang tua/ keluarga pasien di Kecamatan gondangrejo.

Adapun arah korelasi dapat dilihat dari nilai $r$ hitung 0.535 yang berarti ada korelasi yang positif antara kualitas pelayanan praktik RBM dengan kepuasan orang tua/ keluarga pasien di Kecamatan gondangrejo. Sedangkan kekuatan hubungan dapat dilihat dari hasil nilai $\mathrm{r}$ hitung 0.535 , yang menunjukan kekuatan korelasi termasuk "sedang" karena termasuk diantara 0,400 - 0,599.

\section{PEMBAHASAN}

Evaluasi praktik Rehabilitasi Bersumberdaya Masyarakat (RBM) di Kecamatan Gondangrejo sangat penting untuk dilakukan, untuk mengetahui bagaimana kualitas pelayanan praktik
RBM mahasiswa Jurusan Terapi Wicara Poltekkes Kemenkes Surakarta dan bagaiaman kepuasan orangtua/ keluarga pasien dalam mendapatkan pelayanan praktik RBM, oleh karena itu kualitas pelayanan praktik RBM perlu mendapatkan perhatian serius dari Jurusan Terapi Wicara yang menjadikan prakik RBM ini menjadi salah satu keunggulan program studi. Intrumen yang digunakan untuk melihat kualitas pelayanan praktik RBM yang diberikan oleh mahasiwa dengan menggunakan kuesioner yang diberikan kepada orangtua/ keluarga pasien untuk diisi sesuai dengan pertanyaan dikuesioner, pertanyaan ini terdiri dari bentuk fisik (tangibles), kehandalan (reliability), daya tanggap (responsiveness), jaminan (assurance) dan empati (empathy).

Jumlah perempuan yaitu sebesar $73.12 \%$ responden, sedangkan responden laki-laki sebesar 26.9\%, dominasi responden perempuan ini karena latar belakang pola asuh anak yang mayoritas anak diasuh oleh ibunya dan keseharian anak selalu bersama ibunya sehingga pengisian kuesioner ini juga dilakukan oleh ibunya yang tahu perkembangan anaknya. Berdasarkan umur responden, mayoritas responden pada penelitian ini berusia 31 s.d 40 tahun yaitu sebesar $55.8 \%$, hal ini menjukan bahwa rata-rata orang tua yang memilliki anak dengan kebutuhan khusus atau disabilitas adalah usia produktif dimana kesibukan orang tua diluar rumah cukup besar. Berdasarkan tingkat pendidikan responden diketahui bahwa mayoritas tingkat pendidikan responden adalah SLTA yaitu sebesar $61.5 \%$, hal ini menunjukan bahwa tingkat pendidikan di kecamatan godangrejo sudah cukup baik, dengan tingkat pendidikan yang cukup maka pola asuh 
orang tua dalam mendidikan dan mengasuh anak-anaknya juga semakin baik karena dapat belajar dari pengalaman dan teori.

Kualitas pelayanan praktik RBM pada aspek reliability (kehandalan) dari responden menilai "cukup" yaitu sebesar $69.2 \%$ yang menilai "baik" sebesar $15.4 \%$ dan yang "buruk" sebesar $13.5 \%$. Hal ini menunjukan bahwa kualitas pelayanan praktik RBM mahasiswa Jurusan Terapi wicara Poltekkes Kemenkes Surakarta pada aspek kehandalan (reliability) cukup baik dalam hal kedisiplinan, profesional, melakukan prosedur pelayanan dan pelayanan yang diberikan tepat waktu. Mayoritas responden menilai kemampuan bukti fisik yang diberikan oleh mahasiswa masih tergolong "cukup" yaitu sebesar $67.3 \%$, yang menilai "baik" sebesar $19.2 \%$, dan yang menilai "buruk" sebesar $13.5 \%$. Hal ini menujukan bahwa bukti fisik pelayanan praktik RBM oleh mahasiswa Jurusan Terapi Wicara cukup baik dalam penyediaan alat terapi, selalu memakai seragam dan almamater, dan penampilanya sopan dan santun. Mayoritas responden menilai kemampuan daya tanggap (responsiveness) yang tunjukan oleh mahasiswa "cukup" yaitu sebesar 42.3\%, yang menilai "baik" sebesar $19.2 \%$, dan yang menilai "buruk" sebesar $38.5 \%$. Hal ini menujukan bahwa mahasiswa Jurusan Terapi Wiara cukup baik daya tanggapnya di dalam mengatasi permasalahan pasien, mudah ditemui bila orangtua ingin konsultasi, bersedia membantu kesulitan orangtua pasien, memecahkan persoalan, dan menyampaikan informasi dengan jelas.

Mayoritas responden menilai kemampuan jaminan (assurance) yang diberikan oleh mahasiswa "cukup" yaitu sebesar 46.2\%, yang menilai "baik" sebesar $30.8 \%$, dan yang menilai "buruk" sebesar $23.1 \%$. Hal ini menujukan bahwa kemampuan Jaminan (Assurance) yang berikan oleh mahasiswa praktik RBM mengenai kompetensi (Skill) yang dimiliki, perhatian pada pasien, kecermatan dalam pelayanan dan tidak membaut keselahan dalam pelayanan cukup baik. Mayoritas responden menilai kemampuan empati (emphaty) yang ditunjukan oleh mahasiswa "cukup" yaitu sebesar $73.1 \%$, yang menilai "baik" sebesar $15.4 \%$, dan yang menilai "buruk" sebesar $11.5 \%$. Hal ini menujukan bahwa kemampuan Emphaty yang ditunjukan oleh mahasiswa praktik RBM cukup bauk dalam hal : mau dihubungi di luar jam terapi, memberikan motivasi, memperhatikan kepentingan pasien, dan memperlakukan dengan adil berdasarkan analisis univariat menunjukan bahwa mayoritas responden menilai Kualitas pelayanan praktik RBM oleh mahasiswa tergolong "cukup baik" yaitu sebesar $73.1 \%$, yang menilai "baik" sebesar $17.3 \%$, dan yang menilai "buruk" sebesar 9.6\%. Hal ini menujukan bahwa Kualitas pelayanan praktik RBM mahasiswa Jurusan Terapi Wicara cukup baik. Intitusi pendidikan harus melakukan perbaikan untuk meningkatkan kemampuan Kualitas pelayanan praktik RBM agar lebih baik dalam melayani pasien. Mayoritas responden menilai kepuasan keluarga/orang tua pasien tergolong "cukup baik" yaitu sebesar 55.8\%, yang menilai "baik" sebesar $15.4 \%$, dan yang menilai "buruk" sebesar 28.8\%. Hal ini menujukkan bahwa orangtua/ keluarga pasien cukup paus dengan pelayanan praktik RBM mahasiswa Jurusan Terapi Wicara di Kecamatan Gondangrejo. Hasil ini bias digunakan sebagai evaluasi oleh Intitusi Ppendidikan untuk melakukan 
perbaikan dalam meningkatkan kualitas pelayanan praktik RBM agar orangtua/ keluarga/ pasien semakin puas.

Dari hasil uji bivariat dengan menggunakan "Spearman's rho" pada kedua variabel yaitu variabel kualitas pelayanan praktik RBM dan kepuasan orang tua/ keluarga pasien dalam menerima layanan praktik RBM menjukan bahwa ada hubungan yang sangat signifikan antara kualitas pelayanan praktik RBM dengan kepuasan orangtua/ kelaurga pasien di Kecamatan Gondangrejo, hal ini ditunjukan oleh nilai $p$ value 0.000 , yang berarti nilai $p$ value $0.000 \leq 0.05$, dengan arah korelasi yang positif, antara kualitas pelayanan praktik RBM dengan kepuasan orang tua pasien di Kecamatan gondangrejo. Sedangkan kekuatan hubungan dapat dilihat dari hasil nilai $r$ hitung 0.535, yang menunjukan kekuatan korelasi termasuk "sedang" karena termasuk diantara 0,400 - 0,599.

Hasil penelitian ini seiring dengan penelitian yang dilakukan oleh Apriliana et.al (2014) tentang Pengaruh Kualitas Pelayanan Akademik Terhadap Kepuasan Mahasiswa BKK Pendidikan Akuntansi Program Studi Pendidikan Ekonomi Fakultas Keguruan dan Ilmu Pendidikan Universitas Sebelas Maret Surakarta yang hasilnya bukti fisik, kehandalan, daya tanggap dan jaminan berpengaruh positif terhadap kepuasan mahasiswa, sserta penelitian Nurjanah (2013), ia menyatakan bahwa variabel bukti fisik (tangible), keandalan (reliability), daya tanggap (responsivenss), Jaminan (assurance), empati (emphaty) mempengaruhi kepuasan mahasiswa dan loyalitas mahasiswa.

Sedangkan penelitian Aryani dan Rosinta (2010), tentang Pengaruh Kualitas Layanan terhadap Kepuasan Pelanggan dalam Membentuk Loyalitas Pelanggan, menunjukkan bahwa kelima dimensi pembentuk kualitas layanan terbukti berpengaruh secara signifikan terhadap kualitas layanan. Dimensi terkuat dalam menjelaskan kualitas layanan berturutturut adalah reliability, responsiveness, assurance, empathy, dan tangibility.

\section{KESIMPULAN DAN SARAN}

Hasil penelitian ini menunjukkan bahwa terdapat pengaruh yang signifikan antara pengaruh kualitas pelayanan praktik Rehabiltiasi Bersumberdaya Masyarakat (RBM) terhadap kepuasan orang tua/ keluarga pasien di Kecamatan Gondangrejo Kabupaten Karanganyar. Kualitas pelayanan praktik RBM yang dilakukan mahasiswa Jurusan Terapi Wicara secara umum cukup memuaskan orangtua/ keluarga pasien di kecamatan Gondangrejo.

Beberapa saran yang dapat dikemukakan dari hasil penelitian ini adalah sebagai berikut :

1. Bagi institusi pendidikan

a. Senantiasa meningkatkan kerampilan mahasiswa dalam memberikan penatalaksanaan terapi pada pasien di komunitas/masyarakat.

b. Melakukan evaluasi berkala setiap akhir periode praktik untuk memperoleh masukan dari berbagai pihak, terkait kekurangan dan kelebihan praktik RBM.

c. Melakukan kerjasama dengan aparat desa untuk monitoring pelaksanaan praktik RBM di msyarakat agar lebih berkualitas

d. Melakukan case conference untuk membahas kasus-kasus di 
lapangan dengan melibatkan semua unsur

2. Bagi pemerintah desa dan kecamatan

a. Melakukan koordinasi dengan institusi pendidikan terkait pelaksanaan praktik RBM

b. Memonitor pelaksanaan praktik RBM di masyarakat dengan melakukan cross cek kebenaran data dan tindakan terapi oleh mahasiswa

c. Meminta laporan pelaksanaan praktik RBM setiap akhir periode praktik, tentang data pasien di lahan

3. Bagi mahasiswa

a. Selalu meningkatkan ketrampilan praktik klinis dengan mengikuti seminar dan workshop terkait dengan keahlian serta banyak berlatih di masyarakat.

b. Melakukan koordinasi yang instens dengan pembimbing kampus dan pembimbing didesa

c. Selalu berbuat sopan dan santun dalam bertindak, bersikap dan berkomunikasi.

d. Melakukan edukasi dan pelatihan praktis tentang penanganan terapi pada orang tua pasien.

4. Bagi orang tua dan keluarga pasien

a. Bekerjasama dengan mahasiswa untuk melakukan rehabilitasi dan habilitasi pada putra putriya secara mandiri

b. Mendapingi anak-anaknya ketika mendapat penanganan terapi dengan belajar bersama dengan mahasiswa dan anaknya

c. Konsultasi tentang perkembagan anaknya yang diterapi

\section{DAFTAR RUJUKAN}

Arikunto, Suharsimi (2006). Prosedur Penelitian : Suatu Pendekatan Praktek.

BAN-PT, 2012, Pemetaan dan Akreditasi Institusi Farmasi, Badan Akreditasi Nasional Perguruan Tinggi, Jakarta, Indonesia.

Dahlan, M.S.2010. Statistik Untuk Kedokteran Dan Kesehatan : Deskriptif, Bivariat dan Multivariat. Salemba Medika. Jakarta.

Gitosudarmo, Indriyo (2000). Manajemen Pemasaran. Yogyakarta : BPFE

Jurusan Terapi Wicara. 2017. Profil Jurusan Terapi Wicara. Poltekkes Kemenkes Surakarta.

Jurusan Terapi Wicara. 2018. Buku Pedoman RBM Mahaasiwa Jurusan Terapi Wicara. Poltekkes Kemenkes Surakarta.

Kotler, Philip (2002) Manajeman Pemasaran, Edisi Milenium Jakarta PT Prenhalindo.

Kotler, Philip (2005). Manajemen Pemasaran. PT. Indeks. Jakarta.

Lupiyoadi, Rambat. (2001). Manajeman pemasaran jasa. Teori dan Praktik, Edisi Pertama Jakarta. Salemba empat.

Nazir M., 2005. Metode Penelitian. Ghalia Indonesia: Bogor

Notoatmodjo, 2007. Metodologi Penelitian Kesehatan. Edisi Revisi. Rineka Cipta : Jakarta

Nursalam, 2008. Konsep dan Penerapan Metodologi Penelitian Ilmu Keperawatan : Jakarta: Salemba Medika

Oliver, Richard, 1993, A Conceptual Model of Service Quality and Service Satisfaction; Compatible Goal, Different Concept, in Advance in Service 
Marketing and Management, $\mathrm{Vol} 2$; p. $65-85$

Petruzzellis, L., D’Uggento, A.M., and Romanazzi, S. (2006). "Student Satisfaction And Quality Of Service In Italian Universities", Managing Service Quality, Vol.16 No.4, pp.349-364.

Sugiyono,, 2005. Metode penelitian Bisnis, Alfabeta bandung.

Djanali, Supeno. 2003. Pedoman Penjaminan Mutu (Quality Confidence) Pendidikan Tinggi Bidang Akademik. Jakarta: Departemen Pendidikan Nasional Direktorat Jenderal Pendidikan Tinggi.

Supranto, J. (2001). Pengukuran Tingkat Kepuasan Pelanggan. Edisi Baru. PT. Rineka Cipta. Jakarta.

Suranto, Metodologi Penelitian dalam Pendidikan dengan Program SPSS. Semarang: Cv. Ghiyyas Putra, 2009.

Basu Swastha DH. 1998. Asas-asas Marketing. Edisi 3. Yogyakarta. Liberty

Tjiptono F dan A Diana (2003) Total Quality Managemenet. Penerbit Andi. Yogyakarta.

Tjiptono, Fandy \& Chandra, Gregorius. (2005). Service Quality \& Statisfaction. Edisi II. Yogyakarta : Penerbit Andi.

Tjiptono, Fandi, (1997). Strategi Pemasaran, Penerbit Andi offset, edisi kedua, Cetakan pertama Yogyakarta.

Tjiptono, Fandy (2006). Manajemen Jasa. Edisi Keempat. Andi. Yogyakarta

Tjiptono.Fandi dan Diana Anastasia.(2003). Total Quality Manajemen. Yogyakarta. Andi Offset.

Umar H (1999), Metodologi Penelitian Aplikasi dalam pemasaran, Jakarta,
PT Gramedia Pustaka Utama

Wibowo (2009). Manajemen Kinerja. Jakarta : PT. Raja Grafindo Persada

Yamit, Zulian, 2004. Manajemen Kualitas Produk dan Jasa,Ekonesia, Yogyakarta. 